\title{
15.1
}

\section{Определение толщины поляризованной области стекла}

\author{
() А.И. Дергачев ${ }^{1}$, В.В. Журихина ${ }^{2,3,9}$, А.А. Липовский ${ }^{2,3}$ \\ ${ }^{1} \mathrm{OOO}$ „ТЕСКАН“, Санкт-Петербург, Россия \\ ${ }^{2}$ Санкт-Петербургский национальный исследовательский Академический университет им. Ж.И. Алфёрова РАН, \\ Санкт-Петербург, Россия \\ ${ }^{3}$ Санкт-Петербургский политехнический университет Петра Великого, Санкт-Петербург, Россия \\ ๑E-mail: zhurihina_vv@spbstu.ru
}

Поступило в Редакцию 12 ноября 2020г.

В окончательной редакции 12 ноября 2020 г.

Принято к публикации 20 ноября 2020 г.

\begin{abstract}
Показано, что рассеяние электронов вблизи границы поляризованной в воздушной атмосфере и неполяризованной областей стекла дает возможность определения толщины поляризованной области по изображению, получаемому с помощью сканирующего электронного микроскопа. Продемонстрировано хорошее согласие толщин, определенных по изображениям электронного микроскопа и с помощью энергодисперсионного анализа.
\end{abstract}

Ключевые слова: стекла, поляризация, энергодисперсионный анализ, электронная микроскопия.

DOI: 10.21883/PJTF.2021.05.50670.18614

Многокомпонентные силикатные стекла, содержащие как способные к перемещению ионы-модификаторы [1], так и неподвижный сеткообразователь (кремний), позволяют модифицировать их приповерхностную область посредством термической поляризации. При поляризации таких стекол за счет ухода под действием электрического поля щелочных ионов в глубь стекла изменяются состав [2] и структура [3] поляризованной прианодной области, ее показатель преломления [4], объем [5], также у стекла появляется способность генерировать вторую оптическую гармонику за счет снятия электрическим полем центральной симметрии материала [6]. Эти изменения представляют интерес для создания элементов и структур для фотоники $[7,8]$. Толщину поляризованной области, частично или полностью обедненной щелочными ионами, определяют по концентрационным профилям этих ионов. В работе впервые показано, что размер поляризованной области может быть определен по полученному с помощью сканирующего электронного микроскопа (СЭМ) изображению скола образца.

В исследованиях использовались пластинки промышленного натриево-кальциево-силикатного стекла, состав которого представлен в таблице. Толщина пластинок составляла $1 \mathrm{~mm}$.

Эксперименты по поляризации проводились в воздухе 1) с использованием коронного разряда при температуре $300^{\circ} \mathrm{C}$ при постоянном напряжении $3500 \mathrm{~V}$, длительность поляризации составляла $3.5 \mathrm{~h}$; 2) с использованием прижатого к стеклу стеклоуглеродного анода при напряжениях 700 или $1100 \mathrm{~V}$ и температуре $300^{\circ} \mathrm{C}$. Во втором случае выбирались различные длительности поляризации. В процессе поляризации контролировались ток и электрический заряд, прошедший через образец. После поляризации с помощью сканирующего электронного микроскопа TESCAN LYRA3 системой энергодис- персионного элементного микроанализа (ЭДС) Oxford Instruments Aztec Live Automated измерялся концентрационный профиль прианодной области образца. Энергия электронов в луче составляла $8 \mathrm{keV}$. ЭДС-измерения нечувствительны к водороду, проникающему в стекло в процессе поляризации в виде ионов гидрония $\mathrm{H}_{3} \mathrm{O}^{+}$[9], которые образуются в результате разложения на аноде атмосферных водяных паров [10]. Вхождение водорода в стекло было косвенно подтверждено различием профилей концентрации кремния в субанодной области образца, построенных согласно количеству отсчетов импульсов и рассчитанных исходя из состава стекла за вычетом щелочных ионов (см. таблицу). Это заключение также подтверждается тем, что область несовпадения концентрационных профилей кремния соответствовала области, в которой отсутствовал натрий, что непрямым образом указывает на наличие в этой области замещающего натрий водорода [11]. По этой причине в работе использовались концентрационные профили, построенные по количеству отчетов импульсов.

Измеренный в отсчетах импульсов концентрационный профиль натрия в одном из исследованных образцов представлен на рис. $1, a$, а на рис. $1, b$ приведено

Состав исследуемого стекла

\begin{tabular}{c|c}
\hline Оксид & Содержание, wt.\% \\
\hline $\mathrm{SiO}_{2}$ & 72.2 \\
$\mathrm{Al}_{2} \mathrm{O}_{3}$ & 1.2 \\
$\mathrm{Na}_{2} \mathrm{O}$ & 14.3 \\
$\mathrm{~K}_{2} \mathrm{O}$ & 1.2 \\
$\mathrm{MgO}$ & 4.3 \\
$\mathrm{CaO}$ & 6.4 \\
Другие & 0.33
\end{tabular}



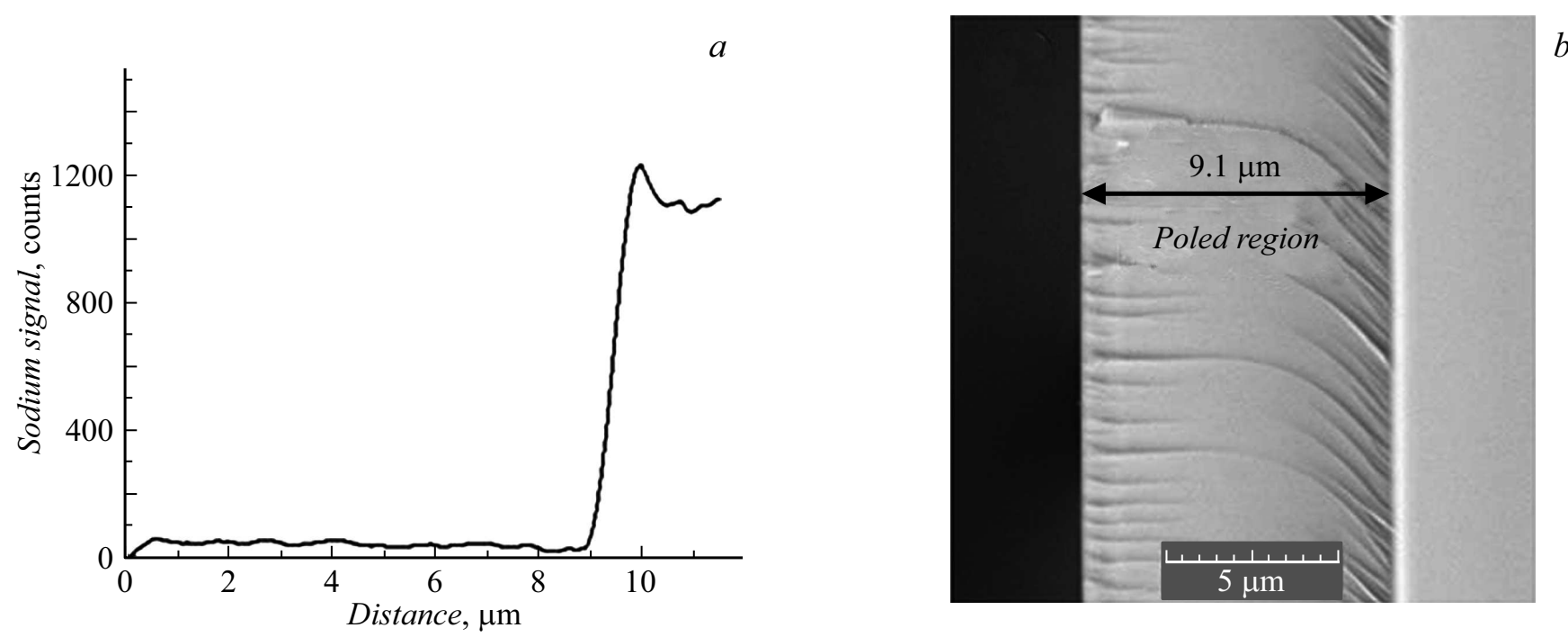

Рис. 1. Профиль концентрации натрия в отсчетах импульсов $(a)$ и СЭМ-изображение скола $(b)$ образца, поляризованного в коронном разряде при напряжении $3.5 \mathrm{kV}$ и температуре $300^{\circ} \mathrm{C}$ в течение $3.5 \mathrm{~h}$.
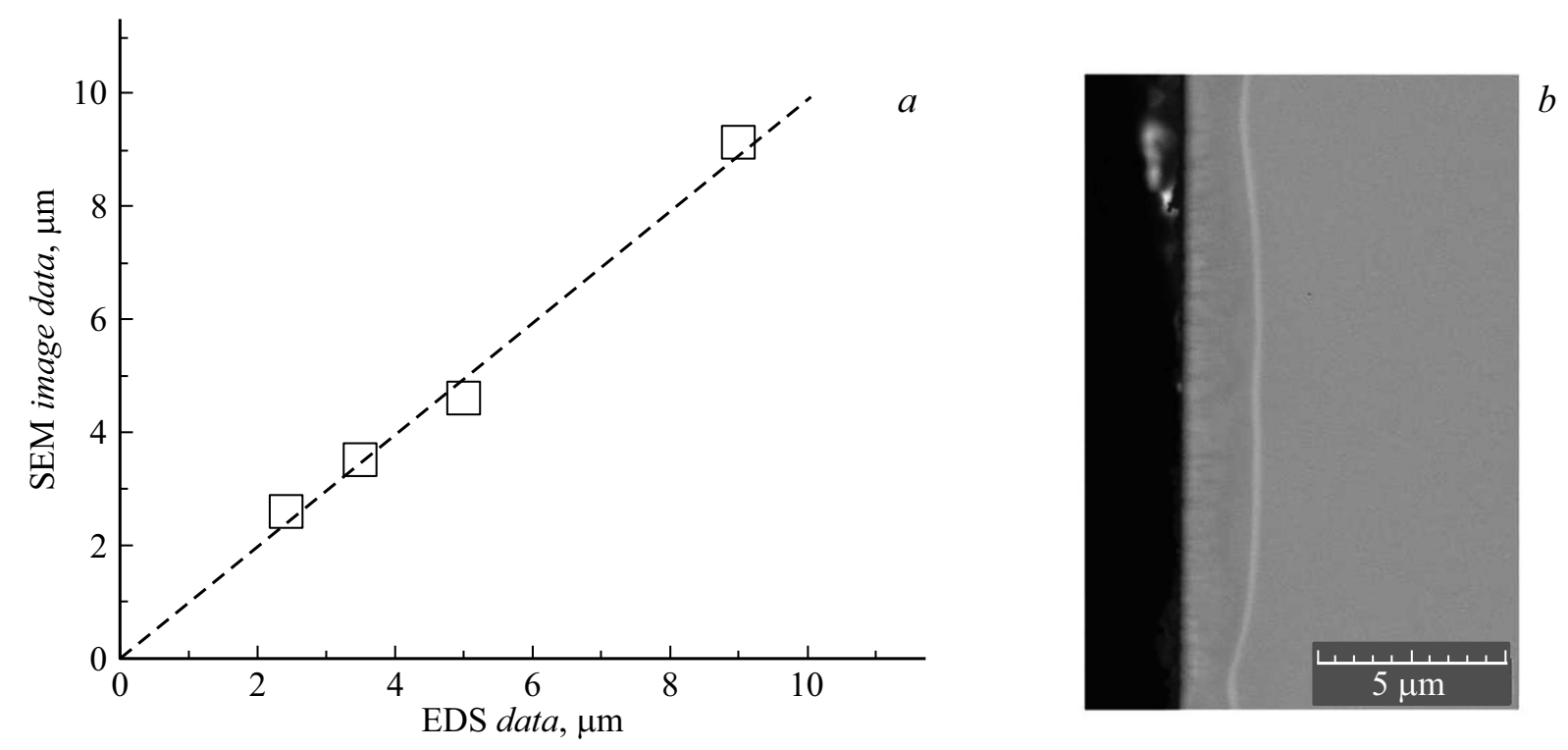

Рис. 2. $a$ - сравнение толщины области изменения концентрации натрия, определенной по ЭДС-профилям и СЭМ-изображениям; $b$ - СЭМ-изображение торца образца стекла, поляризованного с использованием неравномерно прижатого электрода.

СЭМ-изображение скола прианодной области этого образца. Видно, что граница области изменения концентрации натрия соответствует хорошо заметной светлой линии на СЭМ-изображении. Предположительно наличие светлой линии связано с рассеянием электронов областью отрицательного пространственного заряда на интерфейсе содержащих натрий и водород/гидроний областей стекла. Как показывает моделирование [12], формирование этого отрицательного заряда определяется существенным, более чем на три порядка [9], различием подвижностей ионов натрия и водорода/гидрония в силикатных стеклах. Причиной сколов, заметных вблизи поверхности этого сильно поляризованного образца, являются высокие механические напряжения, связанные с изменением локального состава стекла [13].

Сравнение толщин области обеднения стекла натрием, определенных на основе ЭДС-профилей и СЭМ-изображений, иллюстрируется рис. 2,a. Близкие значения толщин, полученных при использовании двух подходов, доказывают возможность определения толщины поляризованной области непосредственно по СЭМ-изображениям. На рис. 2, $b$ представлено СЭМ-изображение торца образца стекла, поляризованного при неравномерном контакте анодного электрода с поверхностью стекла. Неоднородность толщины поляризованной области хорошо заметна. Таким образом, 
СЭМ-изображения могут быть использованы для оценки равномерности поляризации по сечению образца.

\section{Финансирование работы}

Исследование поддержано Министерством науки и высшего образования (проект FSRM-2020-001).

\section{Конфликт интересов}

Авторы заявляют, что у них нет конфликта интересов.

\section{Список литературы}

[1] H. Mehrer, in Diffusion foundations (Trans Tech Publ., Ltd., 2016), vol. 6, p. 59. DOI: $10.4028 /$ www.scientific.net/df.6.59

[2] C.M. Lepienski, J.A. Giacometti, G.F. Leal Ferreira, F.L. Freire, Jr, C.A. Achete, J. Non-Cryst. Solids, 159 (3), 204 (1993). DOI: 10.1016/0022-3093(93)90224-L

[3] A.V. Redkov, V.G. Melehin, A.A. Lipovskii, J. Phys. Chem. C, 119 (30), 17298 (2015). DOI: 10.1021/acs.jpcc.5b04513

[4] R. Oven, Appl. Opt., 55(32), 9123 (2016).

DOI: $10.1364 /$ ao. 55.009123

[5] П.Н. Брунков, В.Г. Мелехин, В.В. Гончаров, А.А. Липовский, М.И. Петров, Письма в ЖТФ, 34 (23), 73 (2008).

[6] G. Poirier, M. Dussauze, V. Rodriguez, F. Adamietz, L. Karam, T. Cardinal, E. Fargin, J. Phys. Chem. C, 123 (43), 26528 (2019). DOI: 10.1021/acs.jpcc.9b08221

[7] G. Yang, J. Cao, Y. Qi, X. He, C. Peng, Y. Lu, F. Tang, K. Tang, B. Liu, H. Chen, G. Chen, Y. Gao, D. Chen, Opt. Mater., 101, 109766 (2020). DOI:10.1016/j.optmat.2020.109766

[8] В.В. Русан, Д.К. Таганцев, А.А. Липовский, К. Пайвасаари, Физика и химия стекла, 36 (4), 642 (2010).

[9] R.H. Doremus, Appl. Phys. Lett., 87 (23), 232904 (2005). DOI: $10.1063 / 1.2140090$

[10] S. Sakata, T. Okada, J. Aerosol Sci., 25 (5), 879 (1994). DOI: 10.1016/0021-8502(94)90054-X

[11] J. Luo, H. He, N.J. Podraza, L. Qian, C.G. Pantano, S.H. Kim, J. Am. Ceram. Soc., 99 (4), 1221 (2016).

DOI: $10.1111 /$ jace.14081

[12] M.I. Petrov, Ya.A. Lepen'kin, A.A. Lipovskii, J. Appl. Phys., 112 (4), 043101 (2012). DOI: 10.1063/1.4742975

[13] H.T. He, J.W. Luo, L.M. Qian, C.G. Pantano, S.H. Kim, J. Am. Ceram. Soc., 99 (4), 1231 (2016). DOI: 10.1111/jace.14080. 